\title{
Institutionalization-Free Survival and Health Care Costs among Quebec Community-Dwelling Elderly Patients with Dementia
}

\author{
Sarah-Gabrielle Beland, ${ }^{1,2}$ Antoine Pariente, ${ }^{3}$ and Yola Moride ${ }^{1,4}$ \\ ${ }^{1}$ Faculty of Pharmacy, Université de Montréal, CP 6128, succursale Centre-Ville, Montreal, QC, Canada H3C 3J7 \\ ${ }^{2}$ Department of Epidemiology \& Biostatistics, McGill University, Montreal, QC, Canada H3A 1A1 \\ ${ }^{3}$ Department of Pharmacology, University of Bordeaux, 146 rue Léo Saignat, 33076 Bordeaux, France \\ ${ }^{4}$ Research Center, University of Montreal Hospital Center (CRCHUM), Montreal, QC, Canada H2W 1T8 \\ Correspondence should be addressed to Yola Moride; yola.moride@umontreal.ca
}

Received 12 July 2013; Revised 29 October 2013; Accepted 1 November 2013; Published 29 January 2014

Academic Editor: Shunichiro Shinagawa

Copyright (C) 2014 Sarah-Gabrielle Beland et al. This is an open access article distributed under the Creative Commons Attribution License, which permits unrestricted use, distribution, and reproduction in any medium, provided the original work is properly cited.

\begin{abstract}
Background. Published data on burden of dementia mainly include patients of third-care facilities. Economic consequences in an outpatient setting remain poorly examined. Objectives. To evaluate institutionalization-free survival and direct health care costs of dementia in the Quebec community-dwelling elderly population. Methods. A retrospective cohort study was conducted using the Quebec administrative claims databases. The cohort included a random sample of patients with treated dementia between January 1, 2000, and December 31, $2009(n=37,138)$. The reference population included elderly patients without dementia matched in age group, gender, and index date. Using a third-party payer perspective, direct costs over 5 years were assessed. Results. Institutionalization-free survival at 5 years was lower in patients with dementia than in elderly without dementia (38.9\% and $72.2 \%$, resp.). Over 5 years, difference in mean total direct health care costs per patient was CAD $\$ 19,159$, distributed into institutionalizations (CAD $\$ 13,598)$, hospitalizations (CAD\$3,312), and prescribed medications (CAD\$2,320). Costs of medical services were similar (-CAD\$96). In the first year of followup, cost differentials were mainly attributable to hospitalizations, while in the last year (year 5) they were due to institutionalizations. Conclusion. This study confirms that dementia is an important socioeconomic burden in the community, the nature of which depends on disease progression.
\end{abstract}

\section{Introduction}

Dementia is a neurodegenerative disease that affected more than 24 million people across the world in 2005 and should reach 81 million in 2040 [1]. Each year, 4.6 million people receive a diagnosis of dementia. Residents of industrialized countries are more affected by dementia than those of nonindustrialized countries [2]. As the prevalence of this disease doubles every five years after the age of 65 , it is estimated that, by 2030 , the number of persons with dementia in the USA alone will reach 7.7 million; by 2050, when the majority of the baby boomers will reach 85 years of age, there will be over 13 million Americans with dementia [3]. Alzheimer's disease (AD) is the most frequent aetiology of dementia in patients of age 65 years and older [4] and is the seventh leading cause of death in the USA [4]. Over the past few years, its prevalence has greatly increased owing to an increase in life expectancy and ageing of the population [5]. The prevalence of dementia varies according to various factors, such as age, comorbidity, genetics, and education. Natural history of the disease is characterized by a worsening of cognition (thinking, reasoning, and memory) and of functional abilities (e.g., activities of daily living), as well as behaviour and mood disorders. As of today, there are no treatments to stop the progression of dementia. At best, current pharmacological treatments delay disease progression.

Currently, the main therapeutic class for the treatment of mild to moderate dementia is acetyl cholinesterase inhibitors (ChIs), which include donepezil, rivastigmine, and galantamine, while memantine is prescribed for moderately severe to severe dementia. The efficacy of ChIs has been demonstrated in randomized controlled trials for outcomes such as cognition, global function, and behavioral symptoms as well as on delaying institutionalization. 
Dementia is associated with an important economic burden, with costs incurred by the health care sector, social care sector, and formal or informal caregivers [6]. It is also known that caregiver burden can predict institutionalization of the person with dementia $[7,8]$. Such burden on the caregivers can also affect their quality of life through decreased mental well-being caused by stress and worry and also the opportunity cost of reduced time for leisure activities and self-care [9].

Worldwide, direct health care costs associated with $\mathrm{AD}$ and other dementias have been estimated to be US $\$ 600$ billion annually [10]. Data on the economic consequences of dementia remain scarce in the literature, the most recent findings originating from the USA [11] or China [12, 13]. The majority of published studies include institutionalized patients, which account for only $51 \%$ of the population with dementia in Canada $[14,15]$. We conducted a study to evaluate the survival and time to institutionalization among patients with dementia compared to those without diagnosed dementia. In addition, the direct health care costs associated with dementia in the community-dwelling elderly population over the short term (one year) and longer term (five years), using a third-party payers perspective, were also determined. A secondary objective was to identify the principal determinants of costs over time.

\section{Methods}

2.1. Study Design. A retrospective cohort study was conducted using the health care databases of the province of Quebec (Canada). The target population was that of communitydwelling elderly patients (age 66+) with treated dementia. Due to the likely underreporting of dementia diagnosis in administrative claims data, ChI dispensing was used as a marker for dementia. In Quebec, reimbursement of ChI initiation is restricted to those patients with mild to moderate dementia who experience functional impairment. Reimbursement of $\mathrm{ChI}$ is conditional on the cognitive status of the patient. Treatment may be initiated in patients with a MiniMental State Examination (MMSE) score ranging from 10 to 26 (or 27 to 28, under exceptional circumstances). Assessment of the patients in 5 domains must also be provided: cognition, mood, behavior, activities of daily living, and social abilities. Reimbursement is initially granted for 6 months (initial prescription 5 refills). After this initial period, renewals are conditional on treatment effectiveness: MMSE score must remain at least 10 , and a maximum decrease of 3 points in the past 6 months is allowed. In addition, stabilization or improvement of symptoms of at least 1 of the 5 domains must be observed. With these conditions for the reimbursement, we believe that all patients using ChIs really suffer from dementia. Cholinesterase inhibitors include donepezil (ARICEPT), rivastigmine (EXELON), or galantamine (REMINYL). Main study outcomes were direct health care costs (drugs, medical services, hospitalizations, and institutionalizations) over a follow-up period of one year and five years after ChI treatment initiation. Costs of health care usage among elderly with dementia were compared to those in a cohort of community-dwelling elderly without a diagnosis of dementia.

2.2. Data Sources. Four Quebec health care databases were used, namely, (1) the prescription claims database of the public drug program (RAMQ prescription database), (2) the medical services claims database of the public health care program (RAMQ medical services database), (3) the beneficiary database of the drug plan members, and (4) the provincial hospital discharge database (MED ECHO). The Quebec public drug program covers outpatient prescriptions for over $97 \%$ of residents of age 65 and over. Inpatient prescriptions, overthe-counter medications, drugs not included in the formulary of reimbursed medications of the public drug program, For each claim, the following informatio or those out-of-pocket are not included in the database. The RAMQ prescription database collects information on the name of the drug, number of units dispensed, dosage, prescribed duration, date of dispensing, and costs (including pharmacist dispensing fee). The Quebec medical services program is universal; that is, it covers all residents of the province regardless of age or income. The RAMQ medical services database includes all claims submitted by physicians according to a fee-forservice payment structure. For each claim, the following information is recorded in the database: type of service or procedure (coded according to the Canadian classification of diagnostic, therapeutic, and surgical procedures), date, location (private practice, emergency department, hospital, long-term care unit, or institution), diagnostic code (ICD-9 classification), and costs. Institutionalization was identified through the location of the medical services. Because the date of death is unavailable in the database, absence of medical and pharmaceutical services for at least 3 months was used as a proxy for death. This algorithm to ascertain death has been validated in a previous study and was found to be 96\% accurate [16]. Discharges from the great majority of Quebec hospitals are recorded in the MED ECHO database. For each discharge, the following information is available: date of admission and discharge, main diagnosis, and up to 10 secondary diagnoses. Diagnoses were coded using ICD-9 until March 31, 2006, and ICD-10 ever since.

2.3. Study Population. Given the extensive underascertainment of dementia in physician claims data, dementia was ascertained using ChI dispensing [17]. ChIs are used by demented elderly to control for their loss of memory. Cholinesterase inhibitors increase the level of a brain chemical called acetylcholine. People with dementia have decreased brain levels of this neurotransmitter. Increasing the amount of acetylcholine appears to slow mental decline in people with dementia. However, it is known that this drug does not work in all demented elderly. Considering that, the rate of false positive is really low, but we know that it is possible that we miss some patients. Drug plan members of age 66 and over who were dispensed ChIs between January 1, 2000, and December 31, 2009, were included in the cohort of community-dwelling patients with dementia. The date of entry in the cohort was the date of first dispensing of a ChI during the study period. To avoid misclassification of 
exposure by patients who filled a first prescription but never took the drug, only those patients who received at least one refill during the year after the initial dispensing were eligible. Patients who had received medical services in long-term care units in the year prior to cohort entry were excluded.

2.4. Comparison Cohort. A comparison cohort of community-dwelling elderly without diagnosed dementia, matched in a $1: 1$ ratio for sex, age group $(65-69 ; 70-74 ; 75-79 ; 80-84$; 85 and over), index year, and month, was created through a random sample of elderly drug plan members with no diagnosis of dementia or dispensing of $\mathrm{ChI}$ or memantine during the study period (2000-2009).

2.5. Followup. Patients were followed for up to five (5) years after index date or until the first of the following censoring events: (i) death or (ii) end of study period (December 31, 2009). For the analysis of institutionalization-free survival, institutionalization was also a censoring criterion.

2.6. Resource Use and Costs. Health care resources used by patients with and without dementia were identified through the occurrence and frequency of physician encounters, medical interventions or procedures, dispensed medications, institutionalizations, and hospitalizations. The number of days of hospitalization was determined using MED ECHO database and the number of days of institutionalization over the 5-year followup was determined using the location where medical services were rendered. Hospitalization costs were based on an index called Niveau d'Intensité Relative des Ressources Utilisées (NIRRU) provided in the MED ECHO database [18]. The NIRRU is a measure of inpatient resources used by a patient or a group of patients. Costs were obtained by multiplying this index by the calendar year's adjusted average cost of acute-care hospitalization in Quebec. Institutionalization costs were calculated using the duration of the stay and the National List of Provincial Costs for Health Care [19]. Medical history was ascertained at the index date, using data on medications dispensed in the previous year. Drugs of interest were those found to be significantly associated with the risk of death in the outpatient elderly population, as determined in a previous study that we have conducted [20]. At-risk patients were those who were dispensed the following drugs: anxiolytics, acetyl salicylic acid (ASA), antidepressants, nonsteroidal anti-inflammatory drugs (NSAIDs), lipid-lowering agents, antihypertensives, and hypoglycemic agents. In addition, history of cerebrovascular disease was assessed.

2.7. Perspective. This study was performed according to the perspective of public third-party payers. Accordingly, only direct health care costs covered by the public health care program were considered in the analysis. The RAMQ databases (medical services and drugs) record, respectively, physicians and pharmacists fee-for-service billings, which are direct health care costs. For drugs, the cost includes the drug cost and the dispensing fee but excludes the deductible and copayment paid by the patient.

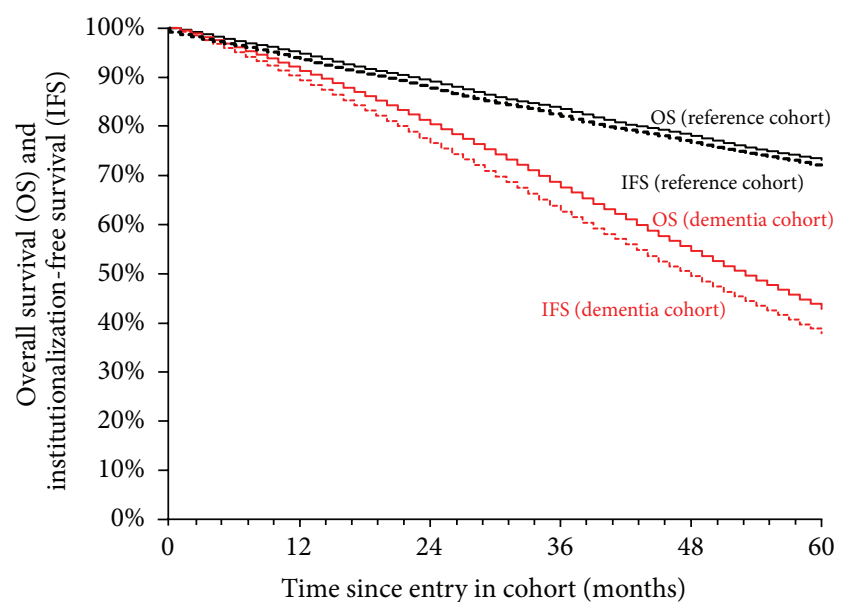

FIGURE 1: Overall survival (OS) and institutionalization-free survival (IFS) among patients with and without dementia over five years after index date.

2.8. Statistical Analysis. For the descriptive analysis of study participants and use of health care resources, we calculated means (standard deviations, SD) and proportions, where appropriate. Mean difference in resource utilization and costs were compared using $t$-test or nonparametric approaches (Wilcoxon). Analyses of differences in costs between the two cohorts took into account death during followup.

Time-to-event analysis, which corresponds to overall survival (OS), and institutionalization-free survival (IFS), defined as the delay between index date (i.e., date of entry in the cohort) and date of death or of institutionalization, respectively, were used. Survivals in each cohort at one year and at five years after index date were compared using a logrank test.

Level of statistical significance was set at 0.05. All analyses were conducted using SAS version 9.2 (SAS Institute, Cary, NC, USA).

2.9. Ethical Considerations. The study was approved by the Ethics Committee of the Université de Montréal as well as the Quebec Privacy Commissioner. All identifiers (patients, physicians, and institutions) were encrypted.

\section{Results}

3.1. Demographic Characteristics. A total of 37,138 patients were included in the cohort of community-dwelling elderly with treated dementia, who were matched to 37,138 elderly in the comparison cohort. Baseline characteristics of the study population are shown in Table 1 . More than $50 \%$ of the study population was aged 80 and over. ChIs prescribed at treatment initiation consisted of donepezil $(70.2 \%)$, galantamine $(17.9 \%)$, or rivastigmine $(11.9 \%)$. Very few patients used memantine $(\leq 0.01 \%)$.

3.2. Risk of Death and Institutionalization. As shown in Figure 1 for the dementia cohort, overall survival (OS) was 
TABLE 1: Distribution of the characteristics of the study population at index date.

\begin{tabular}{|c|c|c|c|}
\hline & $\begin{array}{c}\text { Cohort with treated } \\
\text { dementia } \\
(37,138) \\
n(\%)\end{array}$ & $\begin{array}{c}\text { Reference cohort } \\
(37,138) \\
n(\%)\end{array}$ & $P$ value \\
\hline \multicolumn{4}{|l|}{ Product $^{*}$ at index date } \\
\hline Donepezil & $26,080(70.2)$ & $\mathrm{n} / \mathrm{a}$ & - \\
\hline Rivastigmine & 4,417 (11.9) & $\mathrm{n} / \mathrm{a}$ & - \\
\hline Galantamine & $6,629(17.9)$ & $\mathrm{n} / \mathrm{a}$ & - \\
\hline Memantine & $11(<0.01)$ & $\mathrm{n} / \mathrm{a}$ & - \\
\hline Age group & & & - \\
\hline $65-70$ & $2,141(5.8)$ & $\mathrm{n} / \mathrm{a}^{*}$ & - \\
\hline $70-75$ & $4,965(13.4)$ & $\mathrm{n} / \mathrm{a}$ & - \\
\hline $75-80$ & $9,620(25.9)$ & $\mathrm{n} / \mathrm{a}$ & - \\
\hline $80-85$ & $10,666(28.7)$ & $\mathrm{n} / \mathrm{a}$ & - \\
\hline $85+$ & $9,746(26.2)$ & $\mathrm{n} / \mathrm{a}$ & - \\
\hline Females & $24,471(65.9)$ & $\mathrm{n} / \mathrm{a}$ & - \\
\hline History of cerebrovascular disease & $2,362(6.4)$ & $1,474(4.0)$ & - \\
\hline \multicolumn{4}{|l|}{ History of drug usage } \\
\hline Anxiolytics & $14,732(39.7)$ & $14,670(39.5)$ & 0.64 \\
\hline ASA & $17,839(48.0)$ & $15,842(42.7)$ & $<.001$ \\
\hline Antidepressants & $8,347(22.5)$ & $3,430(9.2)$ & $<.001$ \\
\hline NSAIDs & $6,073(16.4)$ & $8,184(22.0)$ & $<.001$ \\
\hline Lipid-lowering agents & $13,343(35.9)$ & $13,236(35.6)$ & 0.50 \\
\hline Antihypertensives & $34,280(92.3)$ & $26,840(72.2)$ & $<.001$ \\
\hline Hypoglycemic agents & $6,287(16.9)$ & $5,646(15.2)$ & $<.001$ \\
\hline
\end{tabular}

${ }^{*}$ Patients in the reference cohort were matched in age group and gender.

TABLE 2: Health care resource utilization during 1 year and 5 years after index date.

\begin{tabular}{|c|c|c|c|c|c|c|}
\hline \multirow[b]{2}{*}{ Category of utilization } & \multicolumn{3}{|c|}{ Year 1} & \multicolumn{3}{|c|}{ Years 1-5 } \\
\hline & $\begin{array}{c}\text { Dementia } \\
\text { cohort } \\
n=37,138\end{array}$ & $\begin{array}{c}\text { Reference } \\
\text { cohort } \\
n=37,138\end{array}$ & $\begin{array}{c}\text { Difference } \\
(95 \% \mathrm{CI})\end{array}$ & $\begin{array}{c}\text { Dementia } \\
\text { Cohort } \\
n=37,138\end{array}$ & $\begin{array}{c}\text { Reference } \\
\text { Cohort } \\
n=37,138\end{array}$ & $\begin{array}{c}\text { Difference } \\
(95 \% \mathrm{CI})\end{array}$ \\
\hline \multicolumn{7}{|c|}{ Physician visits $^{\dagger}$, number, mean (SD) } \\
\hline Total & $29(36)$ & $23.8(34.2)$ & $5,2(4.7 ; 5.7)$ & $83.4(84.3)$ & $75(92.3)$ & $8.4(7.2 ; 9.7)$ \\
\hline GPs & $19.1(27.9)$ & $12.6(20.6)$ & $6.5(6.1 ; 6.8)$ & $54.5(60.9)$ & $33.7(44.5)$ & $20.8(20.0 ; 21.6)$ \\
\hline Specialists & $9.9(16.8)$ & $11.2(21.1)$ & $-1.3(-1.5 ; 1.0)$ & $28.9(44.6)$ & $41.3(66.6)$ & $-12.4(-13.2 ;-11.6)$ \\
\hline \multicolumn{7}{|c|}{ Hospitalizations $^{\ddagger}$, mean $(\mathrm{SD})$} \\
\hline Length of stay (days) & $8.2(22.2)$ & $4.0(13.4)$ & $4.2(3.9 ; 4.4)$ & $25.7(45.4)$ & $17.8(44.1)$ & $7.9(7.3 ; 8.6)$ \\
\hline \multicolumn{7}{|c|}{ Institutionalizations ${ }^{\dagger}$, mean $(\mathrm{SD})$} \\
\hline Length of stay (days) & $4.0(31.5)$ & $0.4(9.9)$ & $3.6(3.3 ; 4.0)$ & $82.1(308.3)$ & $9.4(115.1)$ & $72.6(69.3 ; 76.0)$ \\
\hline NIRRU index & $.73(1.72)$ & $.53(1.61)$ & $.21(.18 ; .23)$ & $2.18(3.39)$ & $1.51(3.00)$ & $.67(.62 ; .71)$ \\
\hline
\end{tabular}

${ }^{\dagger}$ Source: RAMQ, ${ }^{\ddagger}$ source: MED ECHO.

low at five years $(\mathrm{OS}=42.6 \%)$, compared to the comparison cohort $(\mathrm{OS}=73.2 \%)(P<0.001)$. Institutionalization-free survival rate at 5 years was much lower in patients with dementia (38.9\% and $72.2 \%$, resp., $P<0.001)$. The difference between the dementia and nondementia cohort was less at one year than over the 5-year period for OS $(91.3 \%$ and $96.9 \%$,
$P<0.001)$ and for institutionalization-free survival $(89.3 \%$ and $96.8 \%, P<0.001)$.

3.3. Resource Utilization. In Table 2 the usage of outpatient and inpatient care (using the NIRRU indices) for the first and the five-year follow-up period is shown. It can be observed 
TABLE 3: Direct health care costs (in Canadian dollars) during the first year and five years after index date.

\begin{tabular}{|c|c|c|c|c|c|c|}
\hline & \multicolumn{3}{|c|}{ Year 1} & \multicolumn{3}{|c|}{ Years 1-5 } \\
\hline & $\begin{array}{c}\text { Dementia } \\
\text { cohort } \\
n=37,138\end{array}$ & $\begin{array}{c}\text { Reference } \\
\text { cohort } \\
n=37,138\end{array}$ & $\begin{array}{l}\text { Difference } \\
(95 \% \text { CI })\end{array}$ & $\begin{array}{c}\text { Dementia } \\
\text { cohort } \\
n=37,138\end{array}$ & $\begin{array}{c}\text { Reference } \\
\text { cohort } \\
n=37,138\end{array}$ & $\begin{array}{l}\text { Difference } \\
(95 \% \mathrm{CI})\end{array}$ \\
\hline \multicolumn{7}{|l|}{ Costs CAD\$ (SD) } \\
\hline \multicolumn{7}{|l|}{ Prescription drugs } \\
\hline $\begin{array}{l}\text { Cholinesterase } \\
\text { inhibitors }\end{array}$ & $1,285(651)$ & $\mathrm{n} / \mathrm{a}$ & $1,285(1,278-1,292)$ & $3,638(3,335)$ & $\mathrm{n} / \mathrm{a}$ & 3,638 (3,603-3,672) \\
\hline Other drugs & $1,635(1,766)$ & $1,677(2,054)$ & $-42(-70--15)$ & $5,581(6,952)$ & $6,899(10,160)$ & $-1,318(-1,442--1,192)$ \\
\hline Total drugs & $2,920(2,016)$ & $1,677(2,054)$ & $1,243(1,213-1,271)$ & $9,219(8,974)$ & $6,899(10,160)$ & $2,320(2,182-2,458)$ \\
\hline Physician encounters & $997(1,274)$ & $1,056(1,726)$ & $-60(-81--38)$ & $2,681(2,760)$ & $2,777(3,636)$ & $-96(-142--49)$ \\
\hline Hospitalizations & $3,691(8,631)$ & $2,644(8,083)$ & $1,047(937-1,168)$ & $10,956(17,054)$ & $7,603(15,093)$ & $3,353(3,122-3,585)$ \\
\hline Institutionalizations & $753(5,894)$ & $71(1,843)$ & $682(619-745)$ & $15,344(57,649)$ & $1,763(21,529)$ & $13,581(12,955-14,207)$ \\
\hline Total health care & $8,360(11,667)$ & $5,448(9,970)$ & $2,912(2,756-3,068)$ & $38,200(62,180)$ & $19,041(31,404)$ & $19,159(18,450-19,867)$ \\
\hline
\end{tabular}

that patients with dementia had an average of 29 medical services provided by a physician per year $(\mathrm{SD}=36$; range: $0-514)$ compared to 23 for nondementia patients $(\mathrm{SD}=$ 24; range: $0-826$ ). The difference was statistically significant $(P<0.001)$. An important proportion of those physician encounters were billed by specialists, especially in the cohort of patients without dementia. The mean length of stay in tertiary care units increased exponentially over time among patients in both cohorts. For patients with dementia, the mean duration was 4 days $(\mathrm{SD}=31.5)$ during the first year compared to 82 days $(\mathrm{SD}=308.3)$ during the entire five-year period. In the nondementia cohort, the mean number of days of institutionalization was 0.4 days $(\mathrm{SD}=9.9)$ during the first year and 9.4 days $(S D=115.1)$ for the five years.

3.4. Direct Costs. Over the first year of followup, mean total health care costs were higher for patients with dementia than for patients without dementia: CAD $\$ 8,360$ (SD $\mathrm{CAD} \$ 11,667)$ and $\mathrm{CAD} \$ 5,448$ (SD CAD $\$ 9,970)$, respectively. Most of this difference was accounted for by the costs of ChIs (CAD\$1,285; SD CAD\$651), the remainder of the difference being attributable to institutionalization and hospitalization costs (difference per patient of CAD $\$ 684$ and CAD $\$ 1,103$ for institutionalization and hospitalization costs, resp.).

Over the five-year period, mean total health care costs in the dementia cohort were approximately twice that of the comparison cohort: CAD $\$ 38,200$ (SD CAD $\$ 62,180$ ) and CAD $\$ 19,042$ (SD CAD $\$ 31,346$ ), respectively (Table 3). Cost differences were mainly related to $\mathrm{ChI}$ dispensing $(\mathrm{CAD} \$ 3,638)$, hospitalizations (CAD $\$ 3,312)$, and institutionalizations (CAD $\$ 13,598)$. Even if the mortality rate is high in the dementia cohort (57.4\%) compared to the reference cohort $(26.8 \%)(P<0.001)$, which leads to more frequent censoring in the dementia cohort, overall health care costs still increased significantly over the 5-year period.

Cost differentials were also assessed in subgroups of atrisk patients. With the exception of users of lipid-lowering agents, total health care costs of users of anxiolytics, ASA, antidepressants, antihypertensives, and hypoglycemic agents were greater than among nonusers, throughout the study period. This is rather expected given that these drugs indicate the presence of comorbidity and are associated with death. However, presence of this comorbidity reduces the cost differentials between dementia and nondementia patients. For example, during the first year, difference in total costs between dementia and nondementia patients among antidepressant users was CAD $\$ 1,955$ while the difference was CAD $\$ 2,878$ for nonusers of antidepressants. Similarly, over the five years, the difference in costs between dementia and nondementia patients was CAD $\$ 15,417$ among users and CAD $\$ 19,044$ among nonusers. As shown in Table 4, the same trend was found for all other subgroups of patients with comorbidity, whereby the difference in costs between dementia and nondementia patients was lower when a given comorbidity was present.

\section{Discussion}

Our study confirms that dementia is an important socioeconomic burden for third-party payers. Results show that the overall survival of these patients is low at one year or five years, compared to patients without diagnosed dementia. These findings corroborate prior research findings, which also showed high mortality rates among patients with dementia [21, 22]. Previous studies have indicated that patients above the age of 65 survive for an average of 4 to 8 years after a diagnosis of $\mathrm{AD}$ [23]. Regardless of the cause of death, $61 \%$ of people with $\mathrm{AD}$ at the age of 70 are expected to die before the age of 80 compared with $30 \%$ of persons without $\mathrm{AD}$ [23].

Our study showed that medical services, especially those rendered in an inpatient setting, are the main drivers of costs associated with dementia in Quebec. These results are consistent with those reported in the literature whereby most of the costs among patients diagnosed with $\mathrm{AD}$ originate from hospital care [24]. Syncope, fall, and trauma have been shown to account of $26 \%$ of hospitalizations among patients with $\mathrm{AD}$ [24]. According to cross-sectional data, about $25 \%$ of all hospitalized patients of age 65 years and older have 
TABLE 4: Direct health care costs (in Canadian dollars) according to subgroups of at-risk patients.

\begin{tabular}{|c|c|c|c|c|c|c|}
\hline \multirow[b]{2}{*}{$\begin{array}{l}\text { Patient subpopulation } \\
\text { (determined at index date) }\end{array}$} & \multicolumn{3}{|c|}{ Year 1} & \multicolumn{3}{|c|}{ Years 1-5 } \\
\hline & $\begin{array}{c}\text { Alzheimer cohort } \\
n=37,138 \\
\text { Mean (SD) }\end{array}$ & $\begin{array}{c}\text { Comparison } \\
\text { cohort } \\
n=37,138\end{array}$ & $P$ value & $\begin{array}{c}\text { Alzheimer } \\
\text { cohort } \\
n=37,138\end{array}$ & $\begin{array}{c}\text { Comparison } \\
\text { cohort } \\
n=37,138\end{array}$ & $P$ value \\
\hline \multicolumn{7}{|l|}{$\begin{array}{l}\text { History of cerebrovascular } \\
\text { accident }\end{array}$} \\
\hline Yes & $10,616(13,140)$ & $8,242(12,301)$ & $<.001$ & $44,726(68,115)$ & $28,521(40,417)$ & $<.001$ \\
\hline No & $8,207(11,545)$ & $5,249(9,532)$ & $<.001$ & $37,757(61,732)$ & $18,650(30,852)$ & $<.001$ \\
\hline \multicolumn{7}{|l|}{ Anxiolytic use } \\
\hline Yes & $9,645(12,542)$ & $6,759(10,555)$ & $<.001$ & $41,463(64,007)$ & $23,932(33,989)$ & $<.001$ \\
\hline No & $7,516(10,973)$ & $4,460(8,937)$ & $<.001$ & $36,055(60,856)$ & $15,849(29,053)$ & $<.001$ \\
\hline \multicolumn{7}{|l|}{ Aspirin use } \\
\hline Yes & $9,134(11,978)$ & $6,605(10,467)$ & $<.001$ & $38,776(60,824)$ & $22,564(32,235)$ & $<.001$ \\
\hline No & $7,645(11,325)$ & $4,448(8,929)$ & $<.001$ & $37,667(63,405)$ & $16,422(30,406)$ & $<.001$ \\
\hline \multicolumn{7}{|l|}{ Antidepressant use } \\
\hline Yes & $9,530(12,214)$ & $7,575(11,142)$ & $<.001$ & $40,833(62,711)$ & $25,416(37,278)$ & $<.001$ \\
\hline No & $8,021(11,482)$ & $5,143(9,483)$ & $<.001$ & $37,437(62,006)$ & $18,393(30,605)$ & $<.001$ \\
\hline \multicolumn{7}{|l|}{$\begin{array}{l}\text { Nonsteroidal } \\
\text { anti-inflammatory drug use }\end{array}$} \\
\hline Yes & $8,688(11,639)$ & $6,205(10,322)$ & $<.001$ & $41,509(63,402)$ & $22,247(30,768)$ & $<.001$ \\
\hline No & $8,296(11,672)$ & $5,131(9,470)$ & $<.001$ & $37,553(61,919)$ & $18,136(31,449)$ & $<.001$ \\
\hline \multicolumn{7}{|l|}{ Lipid-lowering drug use } \\
\hline Yes & $8,786(11,249)$ & $6,607(10,125)$ & $<.001$ & $34,773(53,355)$ & $21,352(28,326)$ & $<.001$ \\
\hline No & $8,786(11,889)$ & $4,682(9,345)$ & $<.001$ & $40,121(66,987)$ & $17,763(32,830)$ & $<.001$ \\
\hline \multicolumn{7}{|l|}{ Antihypertensives drug use } \\
\hline Yes & $8,481(11,736)$ & $6,374(10,317)$ & $<.001$ & $38,309(61,979)$ & $21,918(31,823)$ & $<.001$ \\
\hline No & $6,916(10,701)$ & $2,745(7,110)$ & $<.001$ & $36,890(64,541)$ & $11,547(28,748)$ & $<.001$ \\
\hline \multicolumn{7}{|l|}{ Hypoglycemic agent use } \\
\hline Yes & $10,562(13,088)$ & $8,131(11,646)$ & $<.001$ & $42,327(63,140)$ & $27,313(35,781)$ & $<.001$ \\
\hline No & $7,912(11,303)$ & $4,873(9,189)$ & $<.001$ & $37,359(61,950)$ & $17,559(30,246)$ & $<.001$ \\
\hline
\end{tabular}

$\mathrm{AD}$ or other forms of dementia [24]. In our study, costs of hospitalization in patients with dementia were very high in the early year of followup, followed by a switch in the distribution of costs, from hospitalization toward institutionalization, as shown by the high costs of institutionalization at five years. ChIs also accounted for an important portion of cost differentials, although the impact is somewhat offset by a decrease in the use and costs of other drugs. Another important feature is that even if the mortality rate is high in the dementia cohort after 5 years, aggregate costs continue to increase exponentially. Results also showed that the cost differentials across the two populations decrease with age.

In our study, we also examined institutionalization-free survival. Only one-third of patients with dementia were still alive and living in the community at five years. Our findings are consistent with those of a previous study which showed that nursing home admission by the age of 80 is expected for $75 \%$ of patients with dementia compared with only $4 \%$ of the general population [4]. Because the risk of institutionalization increases as patient cognition and functional status decline, direct costs will increase as dementia reaches the severe stage. Consequently, treatments that can delay or reverse disease progression have the potential to reduce direct health care costs, in particular those associated with institutionalization. Furthermore, this study highlights the importance of long-term followup in real-world studies that attempt to assess outcomes of interventions in this population since hospitalization appears to be more relevant in the short term while institutionalization must be an outcome of interest in the longer term.

One of the limitations of our study is that only direct costs were considered, which only accounts for a portion of the burden of illness in this population. Indirect costs such as lost productivity, travel time, and waiting time were not taken into consideration. However, such limitation is attenuated due to the fact that this population typically 
includes patients who are retired. Costs associated with loss in productivity among caregivers, family members, or other assistance such as nurse's aide or housekeeper would be more relevant. Such indirect costs are expected to be much greater in the community-dwelling population with dementia than in institutionalized patients. In addition, costs were assessed through usage of medical services rendered in institutions or long-term care units, as well as through outpatient medical encounters. There may have been misclassification of patients if they had been institutionalized or died outside the province of Quebec. However, such misclassification would likely be minimal and most probably nondifferential across comparison cohorts. On the other hand, claims databases, such as the RAMQ, have been criticized for absence of data on the reliability of diagnostic codes. ChIs products are very specific to dementia and are not prescribed for another indication. Among the inclusion criteria for the study, patients needed to have at least two dispensings of $\mathrm{ChI}$ in a given year to make sure that they were exposed and that they had dementia. Unlike other studies, death and institutionalization are not outcomes that are affected by diagnostic errors in claims database.

Strengths of this study are numerous. Since the use of ChIs is specific to dementia, we are confident that our dementia cohort included only patients with dementia. Furthermore, this study was truly population-based given that the RAMQ database includes the great majority of Quebec elderly residents. Hence, there is no generalizability issue associated with our study. Through the RAMQ claims databases, we were able to conduct a population-based study over the long term. Furthermore, cost parameters were associated with "real-life" patterns of health care use, which provided evidence on the cost of dementia, as opposed to cost-efficacy results that are based on data originating from clinical trials. In addition, the availability of Quebec-specific cost data should be useful to local policy makers, since the most recent data originate from the USA or China, where health care systems differ.

Costs of hospitalization and institutionalization were the most important direct costs in this study. It is worth noting that in Canada the economic burden of AD in 2008 was estimated at $\$ 15$ billion and it is expected to reach $\$ 153$ billion by 2038. These costs include direct health care costs, opportunity costs of informal caregivers, and indirect costs [15]. Consequently, effective interventions that delay institutionalization or prevent hospitalization could lead to potential cost savings.

\section{Conflict of Interests}

The authors declare that there is no conflict of interests regarding the publication of this paper.

\section{Acknowledgments}

The authors are grateful to the members of the Department of Statistical Services at the Régie de l'assurance-maladie du Québec and the Quebec Ministry of Health (MED ECHO) for providing them with the necessary data for this study. This study was funded by the Quebec Health Research Council (FRSQ).

\section{References}

[1] C. P. Ferri and M. Prince, "10/66 dementia research group: recently published survey data for seven Latin America sites," International Psychogeriatrics, vol. 22, no. 1, pp. 158-159, 2010.

[2] A. L. Sosa, E. Albanese, B. C. M. Stephan et al., "Prevalence, distribution, and impact of mild cognitive impairment in Latin America, China, and India: a 10/66 population-based study," PLoS Medicine, vol. 9, no. 2, Article ID e1001170, 2012.

[3] A. P. M. Wimo, "World Alzheimer report: the global economic report," Alzheimer Disease International, 2010.

[4] W. Thies and L. Bleiler, "2011 Alzheimer's disease facts and figures," Alzheimer's and Dementia, vol. 7, no. 2, pp. 208-244, 2011.

[5] B. L. Plassman, K. M. Langa, G. G. Fisher et al., "Prevalence of dementia in the United States: the aging, demographics, and memory study," Neuroepidemiology, vol. 29, no. 1-2, pp. 125-132, 2007.

[6] R. J. Luengo-Fernandez and A. Gray, Dementia 2010: The Economic Burden of Dementia and Associated Research Funding in the United Kingdom, Alzheimer's Research Trust, Cambridge, UK, 2010.

[7] S. Elmståhl, B. Ingvad, and L. Annerstedt, "Family caregiving in dementia: prediction of caregiver burden 12 months after relocation to group-living care," International Psychogeriatrics, vol. 10, no. 2, pp. 127-146, 1998.

[8] B. F. O’Donnell, D. A. Drachman, H. J. Barnes, K. E. Peterson, J. M. Swearer, and R. A. Lew, "Incontinence and troublesome behaviors predict institutionalization in dementia," Journal of Geriatric Psychiatry and Neurology, vol. 5, no. 1, pp. 45-52, 1992.

[9] C. M. Bell, S. S. Araki, and P. J. Neumann, "The association between caregiver burden and caregiver health-related quality of life in Alzheimer disease," Alzheimer Disease and Associated Disorders, vol. 15, no. 3, pp. 129-136, 2001.

[10] ADR Group, The Facts on Alzheimer's Disease, 2005.

[11] A. L. Sosa-Ortiz, I. Acosta-Castillo, and M. J. Prince, "Epidemiology of dementias and Alzheimer's disease," Archives of Medical Research, vol. 43, no. 8, pp. 600-608, 2012.

[12] M. Prince, D. Acosta, C. P. Ferri et al., "Dementia incidence and mortality in middle-income countries, and associations with indicators of cognitive reserve: a 10/66 Dementia Research Group population-based cohort study," The Lancet, vol. 380, no. 9836, pp. 50-58, 2012.

[13] Z. Liu, E. Albanese, S. Li et al., "Chronic disease prevalence and care among the elderly in urban and rural Beijing, China-a 10/66 Dementia Research Group cross-sectional survey," BMC Public Health, vol. 9, article 394, 2009.

[14] J. Lindsay and L. Anderson, "Démence et maladie d'Alzheimer," Rapport de surveillance de la santé des femmes, 2001.

[15] Alzheimer Society of Canada, Rising Tide: the Impact of Dementia on Canadian Society, 2010.

[16] S. G. Beland, Développement et validation d'un index de prédiction des risques d'institutionnalisation et de décès pour le contrôle des variables confondantes non-mesurées dans la population âgée, Faculty of Pharmacy, University of Montreal, 2011.

[17] A. Pariente, A. Fourrier-Réglat, T. Ducruet et al., "Antipsychotic use and myocardial infarction in older patients with treated dementia," Archives of Internal Medicine, vol. 172, no. 8, pp. 648$655,2012$. 
[18] R. D. I. A. M .D. Quebec, "Données et statistiques: données sur demande," 2012, http://www.ramq.gouv.qc.ca/fr/donnees-statistiques/sur-demande/donnees-msss/Pages/med-echo.aspx.

[19] S. G. Béland, M. Tournier, G. Galbaud du Fort et al., "Economic impact of nonpersistence with antidepressant treatment in the adult population of Quebec: a comparative cost-effectiveness approach," Value in Health, vol. 14, no. 4, pp. 492-498, 2011.

[20] S. G. Beland, T. Ducruet, C. Tannenbaum, M. Preville, and Y. Moride, "A comorbidity score to predict institutionalization performs better than a score to predict death in a communitydwelling elderly population," Pharmacoepidemiol Drug Safety, vol. 20, supplement 1, pp. S1-S382, 2011.

[21] A. Weiss, Y. Beloosesky, H. Schmilovitz-Weiss, E. Grossman, and M. Boaz, "Serum total cholesterol: a mortality predictor in elderly hospitalized patients," Clinical Nutrition, vol. 32, no. 4, pp. 533-537, 2012.

[22] E. Cereda, C. Pedrolli, A. Zagami et al., "Alzheimer's disease and mortality in traditional long-term care facilities," Archives of Gerontology and Geriatrics, vol. 56, no. 3, pp. 437-441, 2013.

[23] R. Brookmeyer, E. Johnson, K. Ziegler-Graham, and H. M. Arrighi, "Forecasting the global burden of Alzheimer's disease," Alzheimer's and Dementia, vol. 3, no. 3, pp. 186-191, 2007.

[24] J. P. W. Bynum, P. V. Rabins, W. Weller, M. Niefeld, G. F. Anderson, and A. W. Wu, "The relationship between a dementia diagnosis, chronic illness, medicare expenditures, and hospital use," Journal of the American Geriatrics Society, vol. 52, no. 2, pp. 187-194, 2004. 


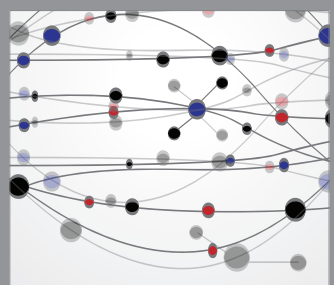

The Scientific World Journal
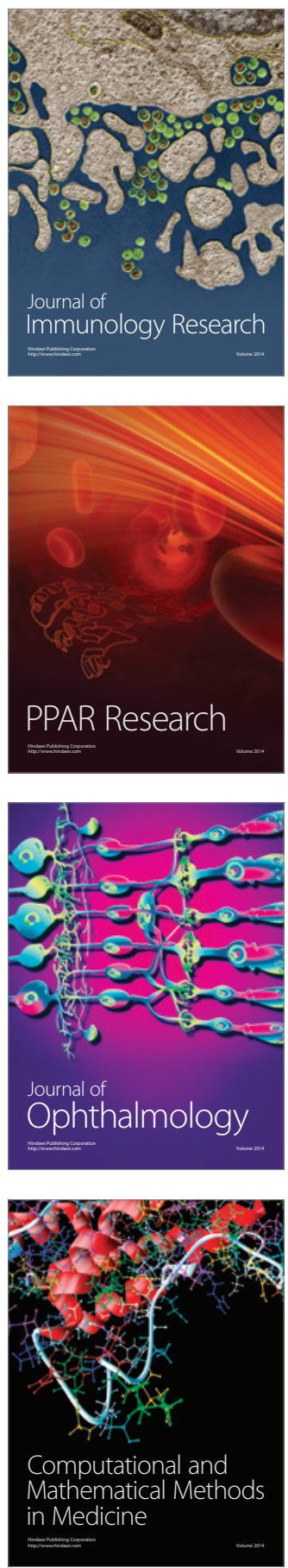

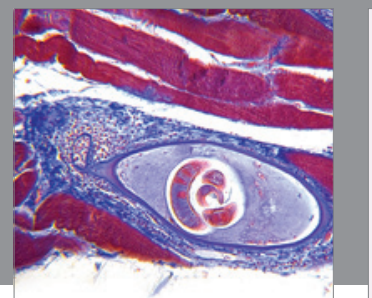

Gastroenterology

Research and Practice
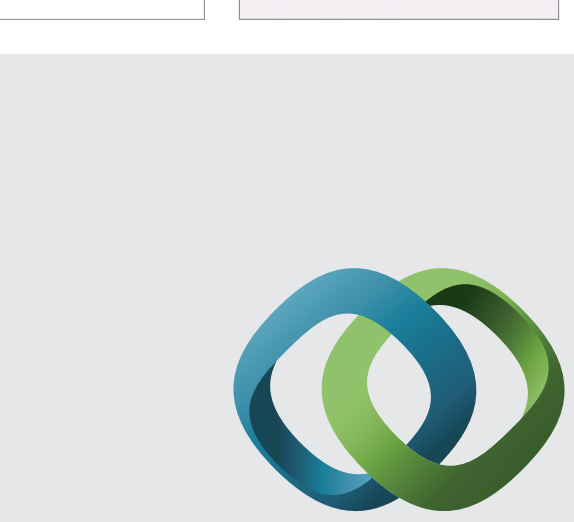

\section{Hindawi}

Submit your manuscripts at

http://www.hindawi.com
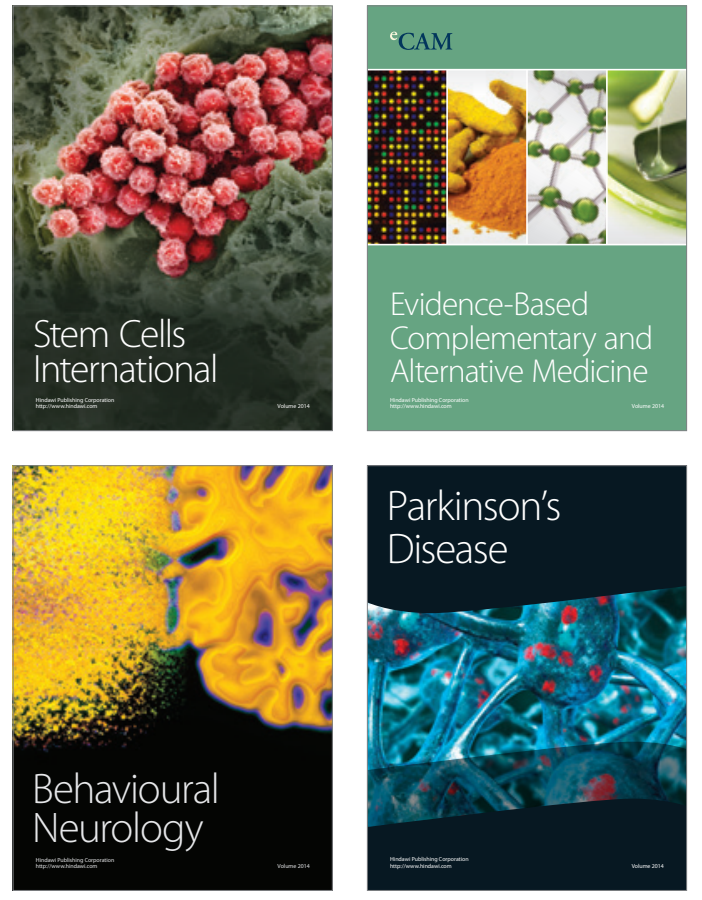
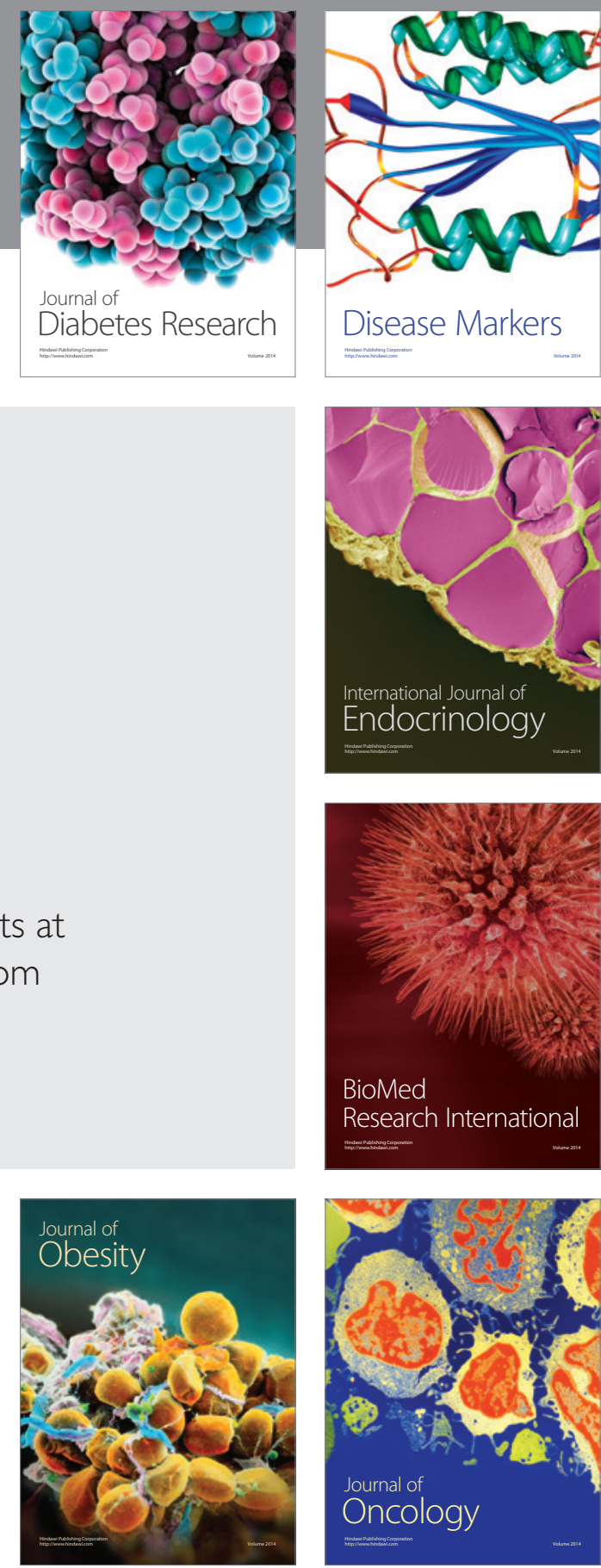

Disease Markers
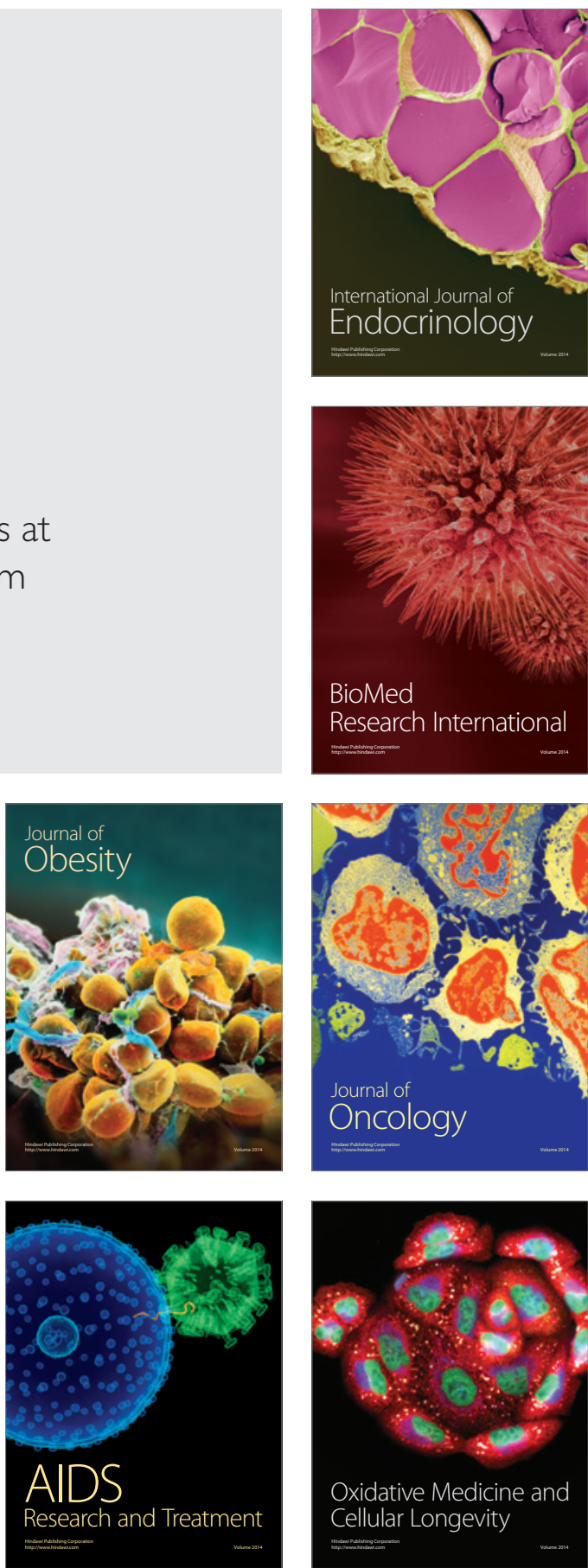